\title{
Formulation of the System of Isohydric Solutions
}

\author{
Tadeusz Michałowski $^{1^{*}}$, Agustin G. Asuero ${ }^{2}$ \\ ${ }^{1}$ Faculty of Engineering and Chemical Technology, Technical University of Cracow, Kraków, Poland; ${ }^{2}$ Department of Analytical \\ Chemistry, The University of Seville, Seville, Spain. \\ Email: *michalot@o2.pl
}

Received November $6^{\text {th }}, 2011$; revised November $30^{\text {th }}, 2011$; accepted December $22^{\text {nd }}, 2011$

\begin{abstract}
The isohydricity ( $\mathrm{pH}$ constancy) as the property referred to mixtures of acids or bases, is illustrated on a simple example of the solutions: $\mathrm{HL}\left(C_{0}, \mathrm{~mol} / \mathrm{L}\right)$ and $\mathrm{HL}(C \mathrm{~mol} / \mathrm{L})$ mixed according to titrimetric mode $(\mathrm{pH}$ titration). A new derivation of the Michałowski formula $C_{0}=C+C^{2} \cdot 10^{p K_{1}}$ expressing this property is presented, and its applicability for determination of $p K_{1}=-\log K_{1}$ value is indicated. The principle of the isohydric method of $p K_{1}$ determination is also outlined.
\end{abstract}

Keywords: Isohydric Solutions; pH Titration

\section{Introduction}

The term "isohydric" refers to solutions of the same hydrogen-ion concentration. According to Arrhenius' statement [1], expressed in more contemporary terms, "if two solutions of the same $\mathrm{pH}$ are mixed, $\mathrm{pH}$ of the mixture is unchanged, regardless the composition of the solutions". This statement is not valid, however, when referred on any pair of electrolytic systems.

To prove it, let us take, for example, the pair of solutions: $C_{1}=10^{-2.5} \approx 0.003 \mathrm{~mol} / \mathrm{L} \mathrm{HCN}\left(p K_{1}=9.2\right)$ and $C_{2}=1$ $\mathrm{mol} / \mathrm{L} \mathrm{AgNO}_{3}\left(\log K_{1}^{\mathrm{OH}}=2.3\right.$ for $\left.\mathrm{Ag}^{+}+\mathrm{OH}^{-}=\mathrm{AgOH}\right)$ [2]. From the approximate formulae: $\left[\mathrm{H}^{+}\right]=\sqrt{C_{1} \cdot K_{1}}$ and $\left[\mathrm{H}^{+}\right]=\sqrt{C_{2} \cdot K_{1}^{\mathrm{OH}} \cdot K_{w}}$ we get $\mathrm{pH}=5.85$, for both solutions. However, as were stated in [3], silver ions when added into HCN solution act as a strong acid, generating protons mainly in the complexation reaction $\mathrm{Ag}^{+}$ $+2 \mathrm{HCN}=\mathrm{Ag}(\mathrm{CN})_{2}^{-}+2 \mathrm{H}^{+}$, and $\mathrm{pH}$ of the mixture drops abruptly. So, the isohydricity property is limited to the systems where only acid-base equilibria are involved. This property was formulated first by Michałowski [4] for different pairs of acid-base systems, then generalized on more complex mixtures of acid-base systems, and extended on mixtures containing basal salts and binarysolvent systems [5]. Moreover, the isohydricity concept was the basis for a very sensitive method of determination of dissociation constants values [4,5].

The present article intends to familiarize the readers with this interesting concept [6] that is in some relevance with buffering action $[7,8]$ and $\mathrm{pH}$-static titration $[9,10]$ principles. Isohydricity concept is also referred to acidbase homeostasis in living organisms [11].

\footnotetext{
"Corresponding author.
}

\section{Principle of Isohydricity}

It is usually stated that an addition of a strong acid $\mathrm{HB}(C$ $\mathrm{mol} / \mathrm{L})$ into a weak acid $\mathrm{HL}\left(C_{0} \mathrm{~mol} / \mathrm{L}\right)$ decreases $\mathrm{pH}$ value of the resulting solution and, consequently, shifts (retracts) the HL dissociation, according to Le Chatelier's principle. As results from Figure 1, the decrease in $\mathrm{pH}$ value $(\mathrm{dpH} / \mathrm{dV}<0)$ and then retracting the dissociation of HL occurs at higher $C$ values, whereas the dilution effect, expressed by $\mathrm{dpH} / \mathrm{dV}>0$, predominates at lower $C$-values. The related effect depends, however, on the HL strength, expressed by its dissociation constant $K_{1}$ value.

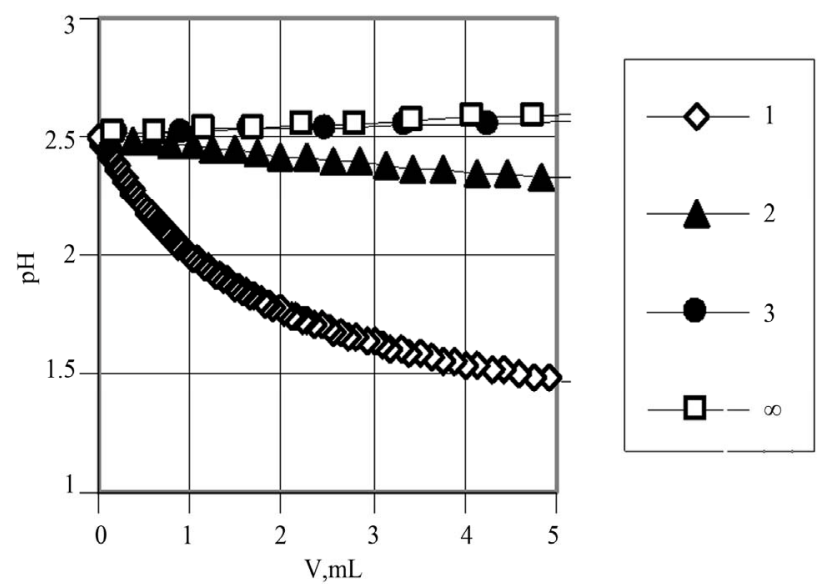

Figure 1. The effect of addition of $V \mathrm{~mL}$ of $C=10^{-p C} \mathrm{~mol} / \mathrm{L}$ strong acid $\mathrm{HB}$ into $V_{0}=10 \mathrm{~mL}$ of $C_{0}=0.1 \mathrm{~mol} / \mathrm{L}$ weak acid $\left(p K_{1}=4.0\right)$. The titration curves $V=V_{0} \cdot\left(\alpha-C_{0} / z\right) /(C-\alpha)$, where $\alpha=10^{-\mathrm{pH}}-10^{\mathrm{pH}-14}, z=10^{p K_{1}-\mathrm{pH}}+1$ are plotted for different $p C=-\log C$ values indicated at the corresponding curves; $p C=1,2,3, \infty$. 


$$
K_{1}=\frac{\left[\mathrm{H}^{+}\right]\left[\mathrm{L}^{-}\right]}{[\mathrm{HL}]}
$$

and on the relative concentrations $\left(C_{0}, C\right)$ of both acids, i.e. HL and HB. Under special conditions, expressed by the set of $\left(C_{0}, C, p K_{1}\right)$ values [4], $\mathrm{pH}=$ const (i.e., $\mathrm{dpH} / \mathrm{dV}=0$ ) when mixing the solutions in different proportions; it is just the subject of the present note.

\section{Formulation of the Isohydricity Concept}

The simplest system of isohydric solutions is composed of a strong monoprotic acid $\mathrm{HB}$ and a weak monoprotic acid HL, characterized by $p K_{1}=-\log K_{1}$ value, where $K_{1}$ is expressed by Equation (1). In order to derive the relation for the isohydricity concept, let us consider the titration of $V_{0} \mathrm{~mL}$ of $C_{0} \mathrm{~mol} / \mathrm{L} \mathrm{HL}$ with $V \mathrm{~mL}$ of $C \mathrm{~mol} / \mathrm{L} \mathrm{HB}$. From charge and concentration balances

$$
\begin{gathered}
{\left[\mathrm{H}^{+}\right]-\left[\mathrm{OH}^{-}\right]=\left[\mathrm{B}^{-}\right]+\left[\mathrm{L}^{-}\right]} \\
{\left[\mathrm{B}^{-}\right]=\frac{C V}{V_{0}+V}} \\
{[\mathrm{HL}]+\left[\mathrm{L}^{-}\right]=\frac{C_{0} V_{0}}{V_{0}+V}}
\end{gathered}
$$

we get

$$
\left[\mathrm{H}^{+}\right]-\left[\mathrm{OH}^{-}\right]=\frac{C V}{V_{0}+V}+(1-\bar{n}) \cdot \frac{C_{0} V_{0}}{V_{0}+V}
$$

where

$$
\bar{n}=\frac{[\mathrm{HL}]}{[\mathrm{HL}]+\left[\mathrm{L}^{-}\right]}
$$

i.e.

$$
1-\bar{n}=\frac{\left[\mathrm{L}^{-}\right]}{[\mathrm{HL}]+\left[\mathrm{L}^{-}\right]}=\frac{K_{1}}{\left[\mathrm{H}^{+}\right]+K_{1}}
$$

Mixing the solutions can be made according to titrimetric mode, in quasistatic manner, under isothermal conditions; it enables some changes in equilibrium constants, affected by thermal effects, to be avoided. As will be seen later, the ionic strength (I) of the related mixture is also secured; it acts in favour of constancy of $\mathrm{K}_{1}$ and ionic product of water, $\mathrm{K}_{\mathrm{W}}=\left[\mathrm{H}^{+}\right]\left[\mathrm{OH}^{-}\right]$during the titration in the system of isohydric solutions. This way, the terms: $\left[\mathrm{H}^{+}\right]-\left[\mathrm{OH}^{-}\right]=\left[\mathrm{H}^{+}\right]-K_{W} /\left[\mathrm{H}^{+}\right]$and $1-n$ (Equation (7)) in Equation (5) are constant at any stage of titration in the isohydric system. In particular, at the start for the titration, i.e. for $V=0$, from (5) we have

$$
\left[\mathrm{H}^{+}\right]-\left[\mathrm{OH}^{-}\right]=(1-\bar{n}) \cdot \mathrm{C}_{0}
$$

Comparing the right sides of (5) and (8), we get, by turns:

$$
\begin{aligned}
& \frac{C V}{V_{0}+V}+(1-\bar{n}) \cdot \frac{C_{0} V_{0}}{V_{0}+V}=(1-\bar{n}) \cdot C_{0} \\
& 1-\bar{n}=\frac{C}{C_{0}} \\
& {\left[\mathrm{H}^{+}\right]-\left[\mathrm{OH}^{-}\right]=C}
\end{aligned}
$$

Then we get, by turns,

$$
\begin{gathered}
{\left[\mathrm{H}^{+}\right]=K_{1} \cdot\left(\frac{C_{0}}{C}-1\right)} \\
{\left[\mathrm{OH}^{-}\right]=\frac{K_{W}}{K_{1}} \cdot\left(\frac{C_{0}}{C}-1\right)^{-1}} \\
K_{1} \cdot\left(\frac{C_{0}}{C}-1\right)=\frac{C}{2} \cdot\left(1+\left(1+\frac{4 K_{W}}{C^{2}}\right)^{1 / 2}\right)
\end{gathered}
$$

Assuming that $4 K_{W} / C^{2} \ll 1$, from (13) we get the formula [4]

$$
C_{0}=C+C^{2} \cdot 10^{p K_{1}}
$$

Identical formula is obtained for reverse titration, where $V_{0} \mathrm{~mL}$ of $C \mathrm{~mol} / \mathrm{L} \mathrm{HB}$ is titrated with $V \mathrm{~mL}$ of $C_{0}$ $\mathrm{mol} / \mathrm{L} \mathrm{HL}$. It means that the isohydricity condition is fulfilled for the set $\left(C_{0}, C, p K_{1}\right)$ where the relationship (14) is valid, independently on the volume of titrant added. The related curves expressed by Equation (14) are plotted for different $p K_{1}$ in Figure 2 within $\left(p C, p C_{0}\right)$ coordinates. The curves appear nonlinearity for lower $p K_{1}$ values and are linear, with slope 2, for $p K_{1}$ greater than ca. 6 . This regularity can be stated from the Equation (14) transformed by turns:

$$
\begin{aligned}
& C_{0}=C^{2} \cdot 10^{p K_{1}} \cdot\left(1+10^{-p K_{1}} / C\right) \\
& p C_{0}=2 \cdot p C-p K_{1}-\log \left(1+10^{p C-p K_{1}}\right)
\end{aligned}
$$

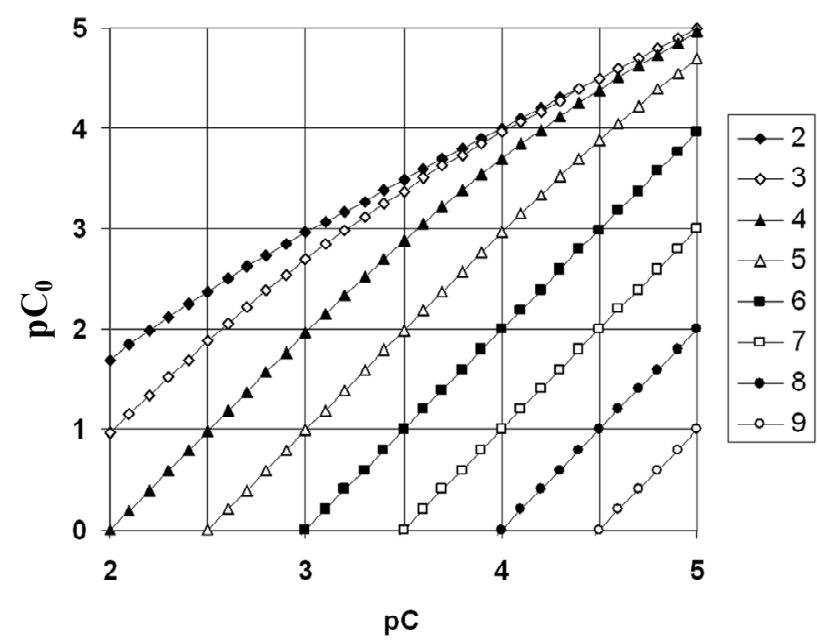

Figure 2. The plots of $p C_{0}=-\log C_{0}$ vs. $p C=-\log C$ relationships obtained on the basis of Equation (14), for different $p K_{1}$ values indicated at the corresponding lines. 
and valid for $p C$ significantly smaller than $p K_{1}$.

It can also be noticed that ionic strength (I) of the solution remains constant during the titration, i.e. it is independent on the volume $V$ of the titrant added. Namely, from (2), (10)-(12) we get

$$
\begin{aligned}
\mathrm{I} & =0.5 \times\left(\left[\mathrm{H}^{+}\right]+\left[\mathrm{OH}^{-}\right]+\left[\mathrm{B}^{-}\right]+\left[\mathrm{L}^{-}\right]\right) \\
& =0.5 \times\left(K_{1}\left(C_{0} / C-1\right)+\left(K_{w} / K_{1}\right) /\left(C_{0} / C-1\right)+C\right)
\end{aligned}
$$

It is the unique property in titrimetric analyses, exploited in the new method of $p K_{1}$ determination, suggested in $[4,5]$. In the light of the Debye-Hückel theory, the constancy in ionic strength (I) is, apart from constancy in temperature $T$ and dielectric permeability $\varepsilon$, one of the properties securing constancy in $K_{1}$ and $K_{W}$ values. Referring again to Figure 1, from Equation (14) we calculate

$$
C=0.5 \cdot 10^{-p K_{1}} \cdot\left(\sqrt{4 \cdot 10^{p K_{1}} \cdot C_{0}+1}-1\right) .
$$

For $C_{0}=0.1, p K_{1}=4.0$ we have $p C=2.507$.

\section{An Isohydric Method of Acidity Constant Determination}

The isohydricity property can be perceived as a valuable tool applicable for determination [4,5] of acidity constant $\left(p K_{1}=-\log K_{1}\right)$ for a weak acid HL, see Equation 1. For this purpose, a series of pairs of solutions (HB (C), HL $\left.\left(C_{0 i}^{*}\right)\right)$ is prepared, where $C$ and $C_{0 i}^{*}$ are interrelated in the formula

$$
C_{0 i}^{*}=C+C^{2} \cdot 10^{p K_{1 i}^{*}}
$$

where $p K_{1 i}^{*}(i=1, \cdots, n)$ are the numbers chosen from the vicinity of the true $p K_{1}$ value for HL. Within each pair (HB $\left.(C), \mathrm{HL}\left(C_{0 i}^{*}\right)\right)$, the $\mathrm{pH}$ titrations $\mathrm{HB}(C, V) \rightarrow$ HL $\left(C_{0 i}^{*}, V_{0}\right)$, are made (see Figure 3). In $[4,5]$, at $V_{0}=3$ $\mathrm{mL}, n=5$ titrations were made up to $V=4 \mathrm{~mL}$. The results of titrations are approximated by straight lines $\mathrm{pH}=$ $a_{i}+b_{i} \cdot V$ (see Figure 4), where $b_{i}$ is the slope of the related line. The plots of the slopes vs. $p K_{1 i}^{*}$ values are usually arranged along the straight or hyperbolic line (Figure 5). The point of intersection with $p K_{1}^{*}$ line, corresponding to the slope $b=0$ (compare with Figure 3) provides an evaluation of the true $p K_{1}$ value, $p K_{1}^{*}=$ $p K_{1}$. Additional, $n+1$ th titration $\mathrm{HB}(C, V) \rightarrow \mathrm{HL}$ $\left(C_{0, n+1}^{*}, V_{0}\right)$, made at $C_{0, n+1}^{*}=C+C^{2} \cdot 10^{p K_{1}}$ provides a confirmation of this $p K_{1}$ value, if $b_{n+1}$ value obtained in this titration is relatively small.

\section{Final Comments}

The new derivation of the formula (14) expressing the isohydricity condition for the simplest case of a mixture composed of strong monoprotic (HB, $C \mathrm{~mol} / \mathrm{L}$ ) and weak monoprotic $\left(\mathrm{HL}, C_{0} \mathrm{~mol} / \mathrm{L}\right.$ ), when mixed according to titrimetric mode, is presented. The roles of titrand and

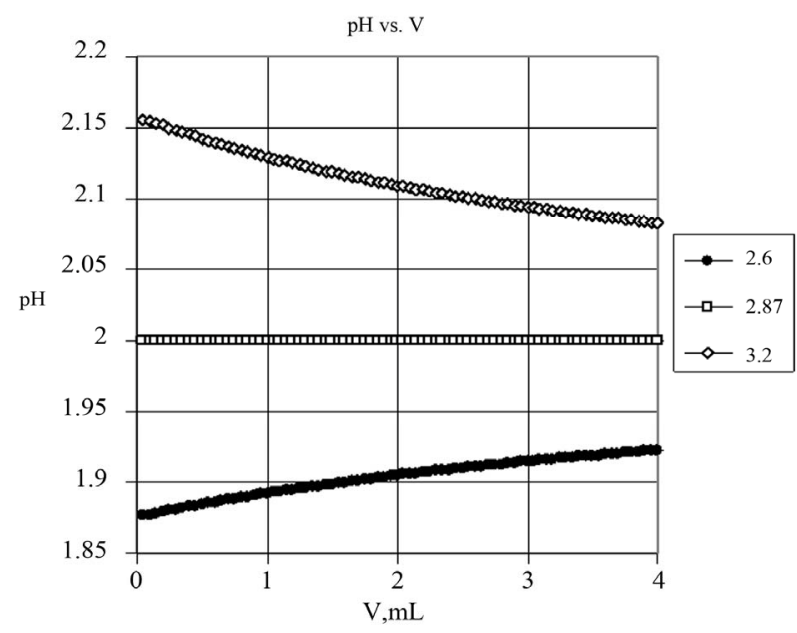

Figure 3. The simulated $\mathbf{p H}$ vs. $V$ relationships plotted for the titration $\mathrm{HB}(C, V) \rightarrow \mathrm{HL}\left(C_{0 i}^{*}, V_{0}\right)$, at $p K_{1}=2.87, V_{0}=3$, $C=0.01$, and $C_{0 i}^{*}$ calculated from Equation (17), at different (indicated) $p K_{1 i}^{*}$ values.

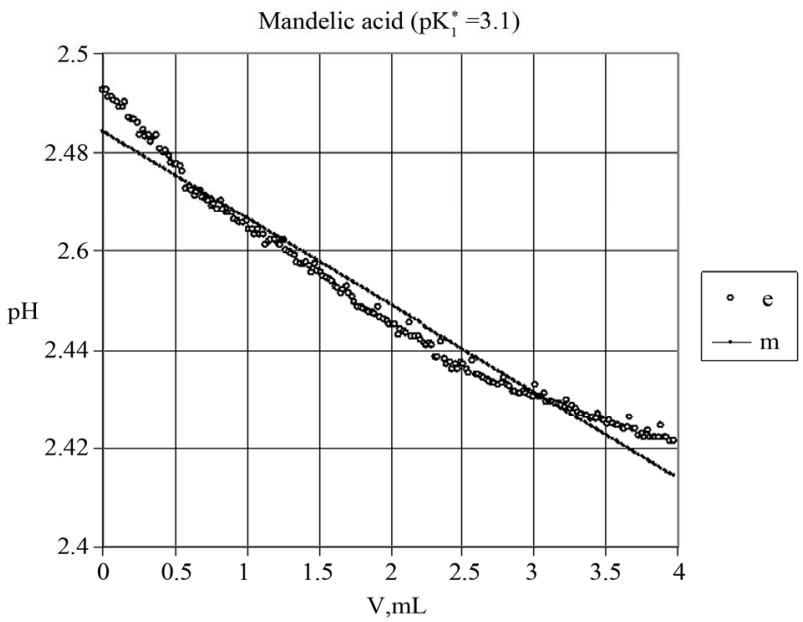

Figure 4. Exemplary approximation of experimental (e) points $\left\{\left(V_{j}, \mathrm{pH}_{j}\right) \mid j=1, \cdots, N\right\}$ by straight line (m) $[4]$.

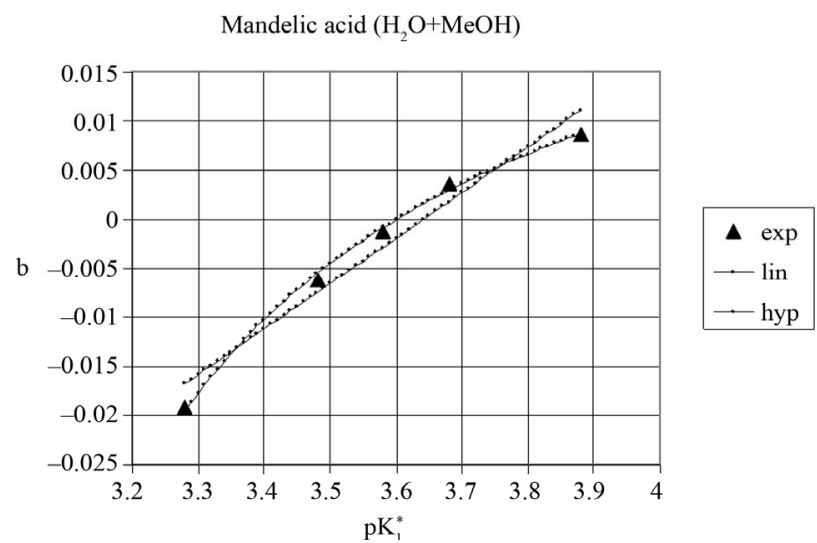

Figure 5. Linear (lin) and hyperbolic (hyp) approximation of experimental $(\exp , \Delta)$ points in $\left(p K_{1}^{*}, b\right)$ co-ordinates [4]. 
titrant in such systems can be reversed. The formulae for more complicated systems are given in [4]. The isohydricity property can be formulated for the systems where only acid-base equilibria occur Equation (14), relates analytical concentrations of strong acid $\mathrm{HB}$ and weak acid HL. Such an interesting property is not directly relevant to buffering action. Nevertheless, it is on-line with a general property desired from buffering systems.

The systems of isohydric solutions have a unique feature, not stated in other acid-base systems. It is the constancy of ionic strength (I), not caused by presence of a basal electrolyte. The conjunction of properties: $\mathrm{pH}=$ const, I = const, together with constancy of temperature $(T=$ const $)$ provided a useful tool for a sensitive method of determination of $p K_{1}$ values for weak acids, as indicated and applied in $[4,5]$. This method is illustrated with some examples taken from [4].

\section{REFERENCES}

[1] S. Arrhenius, "Theorie der Isohydrischen Losungen," Zeitschrift für Physikalische Chemie, Vol. 2, 1888, p. 284.

[2] J. Inczédy, "Analytical Applications of Complex Equilibria," Horwood, Chichester, 1976.

[3] T. Michałowski, M. Rymanowski and A. J. Pietrzyk, "Nontypical Brønsted Acids and Bases," Journal of Chemical Education, Vol. 82, No. 3, 2005, p. 470. doi:10.1021/ed082p470

[4] T. Michałowski, B. Pilarski, A. G. Asuero and A. Dobkowska, "A New Sensitive Method of Dissociation Constants Determination Based on the Isohydric Solutions
Principle," Talanta, Vol. 82, No. 5, 2010, pp. 1965-1973. doi:10.1016/j.talanta.2010.08.024

[5] T. Michałowski, B. Pilarski, A. G. Asuero, A. Dobkowska and S. Wybraniec, "Determination of Dissociation Parameters of Weak Acids in Different Media According to the Isohydric Method," Talanta, Vol. 86, 2011, pp. 447-451. doi:10.1016/j.talanta.2011.09.002

[6] R. de Levie, "On Isohydric Solutions and Buffer pH," Journal of Electroanalytical Chemistry, Vol. 582, No. 1-2, 2005, pp. 21-27. doi:10.1016/j.jelechem.2004.12.028

[7] A. G. Asuero, "Buffer Capacity of a Polyprotic Acid: First Derivative of the Buffer Capacity and $p K_{a}$ Values of Single and Overlapping Equilibria," Critical Reviews in Analytical Chemistry, Vol. 37, No. 4, 2007, pp. 269-301. doi:10.1080/10408340701266238

[8] A. G. Asuero and T. Michałowski, "Comprehensive Formulation of Titration Curves for Complex Acid-Base Systems and Its Analytical Implications," Critical Reviews in Analytical Chemistry, Vol. 41, No. 2, 2011, pp. 151-187. doi:10.1080/10408347.2011.559440

[9] T. Michałowski, M. Toporek and M. Rymanowski, "Overview on the Gran and Other Linearisation Methods Applied in Titrimetric Analyses," Talanta, Vol. 65, No. 5, 2005, pp. 1241-1253. doi:10.1016/j.talanta.2004.08.053

[10] T. Michałowski, M. Toporek and M. Rymanowski, "pHStatic Titration: A Quasistatic Approach," Journal of Chemical Education, Vol. 84, No. 1, 2007, p. 142. doi:10.1021/ed084p142

[11] T. D. DuBose Jr. and L. Lee Hamm, "Acid-Base and Electrolyte Disorders. A Companion to Brenner \& Rector's, The Kidney,” WB Saunders, Philadelphia, 2002. 